\title{
ANALISIS FAKTOR - FAKTOR YANG BERPENGARUH TERHADAP PERSEPSI REMAJA TENTANG PRAKTIK KESEHATAN REPRODUKSI REMAJA DI SMK YPE NUSANTARA SLAWI
}

\author{
Nilatul Izah ${ }^{1)}$, Nora Rahmanindar ${ }^{2)}$ \\ ${ }^{1}$ nilaizah12@gmail.com \\ ${ }^{1,2}$ Prodi D3 Kebidanan Politeknik Harapan Bersama \\ J1. Mataram No. 9 Pesurungan Lor Tegal
}

\begin{abstract}
Abstrak
Remaja merupakan kelompok penduduk dalam jumlah besar. Pengetahuan remaja mengenai kesehatan reproduksi dan cara-cara melindungi dirinya terhadap risiko kesehatan reproduksi masih relatif rendah. Banyak faktor yang menjadi sebab dari persepdi praktik kesehatan reproduksi remaja sangat bervariasi. Penelitian ini bertujuan untuk mengetahui faktor-faktor yang dapat memengaruhi persepsi remaja tentang praktek kesehatan reproduksi remaja di SMK YPE Nusantara Slawi. Penelitian ini merupakan penelitian kuantitatif dengan pendekatan Cross Sectional. Populasi dalam penelitian ini adalah siswa kelas XI SMK YPE Nusantara Slawi. Teknik pengambilan sampel akan dilakukan dengan simple random sampling. Jumlah sampel dalam penelitian ini sebanyak 30 responden. Analisis data dilakukan dengan analisis univariat dan bivariat, analisis univariat dilakukan dengan membuat tabel frekuensi masing-masing variabel. Analisis bivariat dilakukan menggunakan uji Kendall's tau dengan $\alpha=0,05$. Hasil penelitian menunjukkan dari lima faktor yang dianalisis hanya 2 yang memiliki pengaruh yang signifikan terhadap persepsi remaja tentang praktek kesehatan reproduksi remaja yaitu sikap remaja dalam menjaga kesehatan reproduksi dan peran guru dalam memberikan informasi tantang kesehatan reproduksi remaja dengan nilai signifikansi yang sama yaitu $0,046(<0,05)$. Adapun hasil analisis faktor peran orang tuan dalam memberikan informasi tentang kesehatan reproduksi, tingkat pengetahuan dan frekuensi remaja dalam memperoleh informasi tentang kesehatan reproduksi menunjukkan tidak ada pengaruh.
\end{abstract}

Kata kunci: Remaja, Persepsi Praktik Kesehatan Reproduksi Remaja

\section{Abstract}

Teenagers are a large population group. Youth knowledge about reproductive health and ways to protect themselves against reproductive health risks are still relatively low. There are many factors that cause the practice of adolescent reproductive health to vary greatly. This study aims to determine the factors that can influence adolescent perceptions about adolescent reproductive health practices in YPE Nusantara Slawi Vocational School. This research is a quantitative research with Cross Sectional approach. The population in this study were students of class XI SMK YPE Nusantara Slawi. The sampling technique will be carried out by simple random sampling. The number of samples in this study were 30 respondents. Data analysis was carried out by univariate and bivariate analysis, univariate analysis was carried out by making a frequency table for each variable. Bivariate analysis was performed using Kendall's tau test with $\alpha=0.05$. The results showed that only two of the five factors analyzed had a significant influence on teenagers' perceptions of adolescent reproductive health practices, namely the attitudes of adolescents in maintaining reproductive health and the role of teachers in providing information on adolescent reproductive health with the same significance value of $0.046(<0,05)$. As for the results of the role factor analysis of the host in providing information about reproductive health, the level of knowledge and frequency of adolescents in obtaining information about reproductive health shows no influence.

Keywords: Teenagers, Perceptions of Adolescent Reproductive Health Practices 


\section{Pendahuluan}

Remaja merupakan kelompok penduduk dalam jumlah besar karena seperlima dari penduduk didunia terdiri dari remaja. Saat ini lebih dari satu miliar penduduk berusia 10-19 tahun, $70 \%$ diantaranya tinggal di Negara berkembang. Masa remaja terjadi berbagai perubahan fisik, sosial emosional maupun hormonal ${ }^{[1]}$.

Besarnya penduduk remaja akan berpengaruh pada pembangunan dari aspek sosial, ekonomi, maupun demografi baik saat ini maupun dimasa yang akan datang. Penduduk remaja usia 10-24 tahun perlu mendapat perhatian serius karena remaja termasuk dalam usia sekolah dan usia kerja, mereka sangat beresiko terhadap masalahmasalah kesehatan reproduksi yaitu perilaku seksual pra nikah, Narkoba Psikotropika dan Zat adiktif lainya (NAPZA), dan HIV/AIDS ${ }^{[2]}$.

Berdasarkan penelitian yang dilakukan oleh WHO menunjukkan bahwa kurangnya pengetahuan remaja tentang masa subur dapat terlihat pada pengetahuan mereka tentang risiko kehamilan. Sebanyak 19,2\% remaja menyatakan bahwa perempuan yang melakukan hubungan seksual sebelum mengalami menstruasi dapat hamil, dan sebanyak $8,8 \%$ remaja yang mendengar istilah masa subur menyatakan bahwa perempuan tidak bisa hamil bila melakukan hubungan seksual pada masa subur. Kurangnya pengetahuan remaja ini perlu mendapat perhatian karena hubungan seksual antara laki-laki dan perempuan tetap mempunyai risiko untuk hamil. Pengetahuan remaja mengenai kesehatan reproduksi dan cara-cara melindungi dirinya terhadap risiko kesehatan reproduksi masih relatif rendah. Oleh karena itu kesehatan reproduksi remaja perlu mendapatkan perhatian yang lebih ${ }^{[4]}$.

Banyak faktor yang menjadi sebab dari kasus - kasus di atas, diantaranya karena rendahnya pengetahuan yang dimiliki remaja mengenai seksualitas (seks, kontrasepsi, pregnancy, dan lainlain), bahkan seringkali pengetahuan yang selain tidak lengkap itu juga tidak benar, karena diperoleh dari sumber yang kurang tepat, misalnya dari teman sebaya, media informasi seperti majalah porno, film-film biru, dan mitos yang beredar di masyarakat. Karena seharusnya mereka mendapatkan informasi masalah kesehatan reproduksi melalui orang tua, karena informal tentang kesehatan reproduksi yang paling awal tergantung dari pengetahuan orang tua ${ }^{[5]}$.

Perilaku negatif terhadap kesehatan reproduksi remaja diatas, penting untuk diteliti. Ada beberapa faktor yang dapat mempengaruhi perilaku kesehatan reproduksi remaja yaitu mencakup faktor predisposing adalah pengetahuan dan sikap remaja, faktor enabling adalah akses terhadap informasi, serta faktor reinforcing meliputi keluarga, guru dan teman sebaya.

Adanya ketiga faktor tersebut menurut L. Green, menyatakan bahwa tidak ada sebuah perilaku yang disebabkan oleh hanya satu faktor. Semua rencana untuk mempengaruhi perilaku harus dipertimbangkan ketiga faktor kausal tersebut ${ }^{[6]}$.

Penelitian yang dilakukan oleh Hikmah (2002) yang berjudul intensitas komunikasi orang tua dan remaja dengan kesenjangan pengetahuan kesehatan reproduksi di SMA Taman Madya Yogyakarta yang dilakukan secara kuantitatif dengan desain penelitian cross sectional menunjukkan hasil bahwa tidak terdapat hubungan antara intensitas komunikasi orang tua dan remaja dengan kesenjangan pengetahuan remaja tentang kesehatan reproduksi remaja ${ }^{[7]}$.

Penelitian tentang pengaruh pendidikan kesehatan reproduksi melalui metode pendidikan sebaya terhadap pengetahuan dan sikap remaja dalam pencegahan KTD di SMKN 15 Bandung secara kuantitatif dengan pendekatan eksperimental, yang menyimpulkan bahwa pendidikan kesehatan reproduksi melalui metode pendidikan sebaya berpengaruh pada pengetahuan dan sikap remaja dalam pencegahan $\mathrm{KTD}^{[8]}$. 
Penelitian yang berjudul faktor faktor yang berhubungan dengan persepsi remaja kelas $\mathrm{x}$ tentang seksual bebas di SMA muhammadiyah bantul Yogyakarta dengan hasil penelitian menunjukkan variabel yang berhubungan dengan persepsi remaja kelas $\mathrm{x}$ tentang seksual bebas yakni variabel akses media informasi dengan nilai $\mathrm{p} 0,02<0,05^{[9]}$.

Penelitian ini bertujuan untuk mengetahui Faktor-faktor yang dapat memengaruhi persepsi remaja tentang praktek kesehatan reproduksi remaja di SMK YPE Nusantara Slawi.

\section{Metode Penelitian}

Penelitian ini merupakan penelitian kuantitatif. Pendekatan penelitian ini termasuk Cross Sectional karena variabel sebab akibat yang terjadi pada obyek penelitian diukur atau dikumpulkan dalam waktu yang bersamaan. Populasi dalam penelitian ini adalah siswa kelas XI SMK YPE Nusantara Slawi. jumlah populasi dalam penelitian ini yaitu 120 siswa. Teknik pengambilan sampel akan dilakukan dengan simple random sampling. Sampel diambil $25 \%$ dari populasi yaitu sebanyak 30 responden/ siswa. Sumber data diambil melalui pengisian kuesioner oleh responden. Analisis data dilakukan dengan analisis univariat dan bivariat, analisis univariat bertujuan untuk menggambarkan setiap variabel yang diteliti secara terpisah dengan cara membuat tabel frekuensi dari masingmasing variabel. Analisis bivariat dilakukan untuk mengetahui pengaruh dari variabel dependen dan independen, analisis bivariat dilakukan dengan menggunakan uji Kendall's tau dengan $\alpha=0,05$.

\section{Hasil dan Pembahasan}

Tabel 1 Persepsi Responden tentang Praktik Kesehatan Reproduksi

\begin{tabular}{lcc}
\hline $\begin{array}{c}\text { Persepsi tentang } \\
\text { praktik kespro }\end{array}$ & n & $\mathbf{f ( \% )}$ \\
\hline Buruk & 7 & 23,3 \\
Baik & 23 & 76,7 \\
\hline Total & 30 & 100 \\
\hline
\end{tabular}

Tabel 1 menunjukkan sebagian besar responden memiliki persepsi yang baik tentang kesehatan reproduksi remaja yaitu 23 responden $(76,7 \%)$.

Tabel 2 faktor - faktor yang mempengaruhi Persepsi tentang Praktik Kesehatan Reproduksi

\begin{tabular}{|c|c|c|}
\hline $\begin{array}{c}\text { Persepsi Praktik } \\
\text { Kespro }\end{array}$ & $\mathbf{n}$ & $\mathbf{f}(\%)$ \\
\hline \multicolumn{3}{|c|}{ Tingkat Pengetahuan } \\
\hline Baik & 11 & 36,7 \\
\hline Cukup & 16 & 53,3 \\
\hline Kurang & 3 & 10 \\
\hline \multicolumn{3}{|l|}{ Sikap } \\
\hline Mendukung & 20 & 66,7 \\
\hline Ragu - ragu & 7 & 23,3 \\
\hline Tidak & 3 & 10 \\
\hline Mendukung & & \\
\hline \multicolumn{3}{|l|}{ Akses Informasi } \\
\hline Tidak Pernah & & 6,7 \\
\hline Jarang & 2 & 33,3 \\
\hline Sering & $\begin{array}{l}10 \\
18\end{array}$ & 60 \\
\hline \multicolumn{3}{|l|}{$\begin{array}{l}\text { Peran Orang Tua } \\
\text { dalam }\end{array}$} \\
\hline \multicolumn{3}{|l|}{ Memberikan } \\
\hline \multicolumn{3}{|l|}{ Informasi } \\
\hline Menghambat & 3 & 10 \\
\hline Biasa & 15 & 50 \\
\hline Mendukung & 12 & 40 \\
\hline \multicolumn{3}{|l|}{$\begin{array}{l}\text { Peran Guru dalam } \\
\text { Memberikan }\end{array}$} \\
\hline \multicolumn{3}{|l|}{ Informasi } \\
\hline Tidak & 5 & 16,7 \\
\hline Jarang & 12 & 40 \\
\hline Sering & 3 & 43,3 \\
\hline
\end{tabular}

Tabel 2 menunjukkan bahwa tingkat pengetahuan responden tentang kesehata reproduksi sebagian besar berpengetahuan cukup yaitu 53,3\%, sikap responden dalam memelihara kesehatan reproduksinya sebagian besar sudah mendukung yaitu sebanyak $66,7 \%$, akses informasi tentang kesehatan reproduksi yang diperoleh responden sebagian besar sering yaitu sebanyak $60 \%$, peran orang tua dalam memberikan informasi tentang kesehatan reproduksi pada responden sebagian besar biasa yaitu sebanyak $50 \%$ dan peran guru dalam memberikan informasi tentang kesehatan reproduksi 
pada responden sebagian besar adalah

sering yaitu sebanyak

$43,3 \%$.

Tabel 3 Pengaruh Tingkat Pengetahuan terhadap Persepsi Remaja Tentang Praktek Kesehatan Reproduksi Remaja

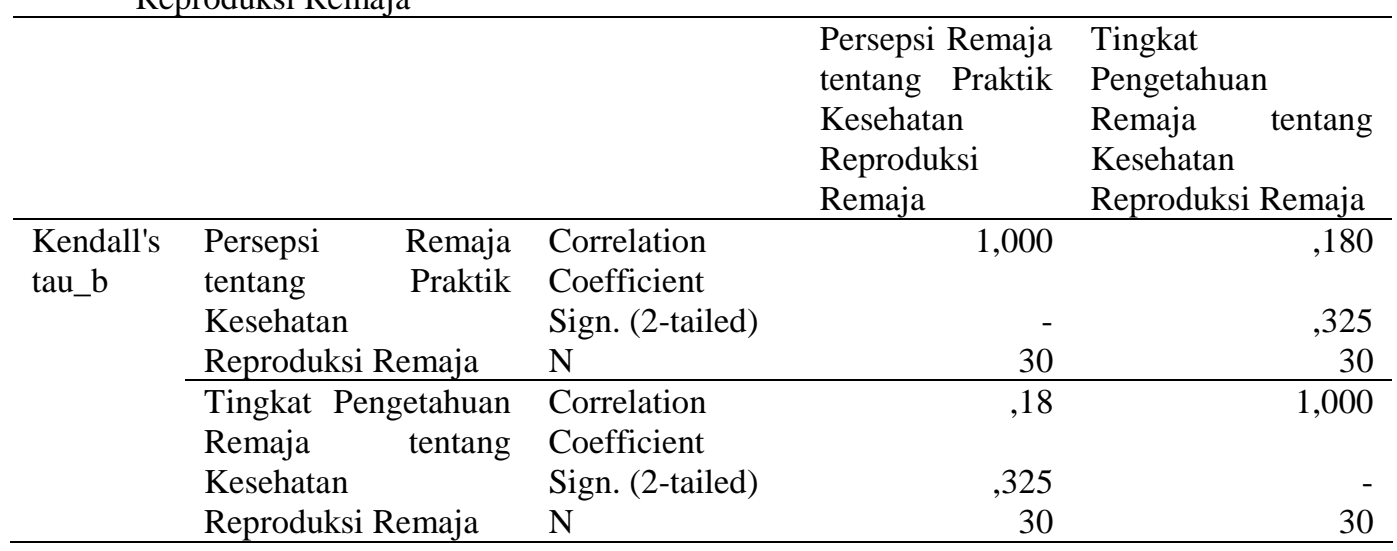

Tabel 3 menunjukkan hasil analisis diperoleh nilai koefisien korelasi sebesar 0,180 dengan nilai signifikansi sebesar 0,325 (> 0,05) menunjukkan bahwa tidak terdapat pengaruh yang signifikan antara tingkat pengetahuan tentang kesehatan reproduksi dengan persepsi remaja tentang praktik kesehatan reproduksi remaja.

Tabel 4. Pengaruh Sikap Remaja dalam Menjaga Kesehatan Reproduksi terhadap Persepsi Remaja Tentang Praktek Kesehatan Reproduksi Remaja

\begin{tabular}{|c|c|c|c|c|}
\hline & & & $\begin{array}{l}\text { Persepsi Remaja } \\
\text { tentang Praktik } \\
\text { Kesehatan } \\
\text { Reproduksi } \\
\text { Remaja }\end{array}$ & $\begin{array}{l}\text { Sikap remaja } \\
\text { dalam menjaga } \\
\text { kesehatan } \\
\text { reproduksi } \\
\text { remaja }\end{array}$ \\
\hline \multirow{8}{*}{$\begin{array}{l}\text { Kendall's } \\
\text { tau_b }\end{array}$} & Persepsi & Correlation & \multirow[t]{2}{*}{1,000} & \multirow[t]{2}{*}{,371 } \\
\hline & tentang & Coefficient & & \\
\hline & Kesehatan & Sign. (2-tailed) & \multicolumn{2}{|r|}{046} \\
\hline & Reproduksi Remaja & $\mathrm{N}$ & 30 & 30 \\
\hline & Sikap remaja dalam & Correlation & \multirow[t]{2}{*}{,371 } & \multirow[t]{2}{*}{1,000} \\
\hline & menjaga kesehatan & Coefficient & & \\
\hline & reproduksi remaja & Sign. (2-tailed) &, 046 & - \\
\hline & & $\mathrm{N}$ & 30 & 30 \\
\hline
\end{tabular}

Tabel 4 menunjukkan hasil analisis diperoleh nilai koefisien korelasi sebesar 0,371 dengan nilai signifikansi sebesar 0,046 (< 0,05) menunjukkan bahwa terdapat pengaruh yang signifikan antara sikap remaja dalam menjaga kesehatan reproduksi remaja dengan persepsi remaja tentang praktik kesehatan reproduksi remaja.

Tabel 5. Pengaruh Frekuensi Remaja dalam memperoleh Informasi tentang Kesehatan Reproduksi terhadap Persepsi Remaja Tentang Praktek Kesehatan Reproduksi Remaja

\begin{tabular}{|c|c|c|c|c|c|}
\hline & & & & $\begin{array}{l}\text { Persepsi Remaja } \\
\text { tentang Praktik } \\
\text { Kesehatan } \\
\text { Reproduksi } \\
\text { Remaja }\end{array}$ & $\begin{array}{lr}\text { Frekuensi } & \text { Remaja } \\
\text { dalam Memperoleh } \\
\text { Informasi tentang } \\
\text { Kesehatan } \\
\text { Reproduksi }\end{array}$ \\
\hline $\begin{array}{l}\text { Kendall's } \\
\text { tau_b }\end{array}$ & $\begin{array}{l}\text { Persepsi } \\
\text { tentang } \\
\text { Kesehatan }\end{array}$ & $\begin{array}{l}\text { Remaja } \\
\text { Praktik }\end{array}$ & $\begin{array}{l}\text { Correlation } \\
\text { Coefficient } \\
\text { Sign. (2-tailed) }\end{array}$ & 1,000 & $\begin{array}{l}337 \\
, 070\end{array}$ \\
\hline
\end{tabular}




\begin{tabular}{llrr} 
Reproduksi Remaja & N & 30 & 30 \\
\hline $\begin{array}{l}\text { Frekuensi Remaja } \\
\text { dalam Memperoleh }\end{array}$ & Correlation &, 337 & 1,000 \\
Informasi tentang & Sign. (2-tailed) & & \\
Kesehatan & $\mathrm{N}$ &, 070 & - \\
Reproduksi & & 30 & 30 \\
\hline
\end{tabular}

Tabel 5 menunjukkan hasil analisis diperoleh nilai koefisien korelasi sebesar 0,337 dengan nilai signifikansi sebesar 0,070 (> 0,05) menunjukkan bahwa tidak terdapat pengaruh yang signifikan antara frekuensi remaja dalam memperoleh informasi tentang kesehatan reproduksi dengan persepsi remaja tentang praktik kesehatan reproduksi remaja.

Tabel 6. Pengaruh Peran Orang Tua terhadap Persepsi Remaja Tentang Praktek Kesehatan Reproduksi Remaja

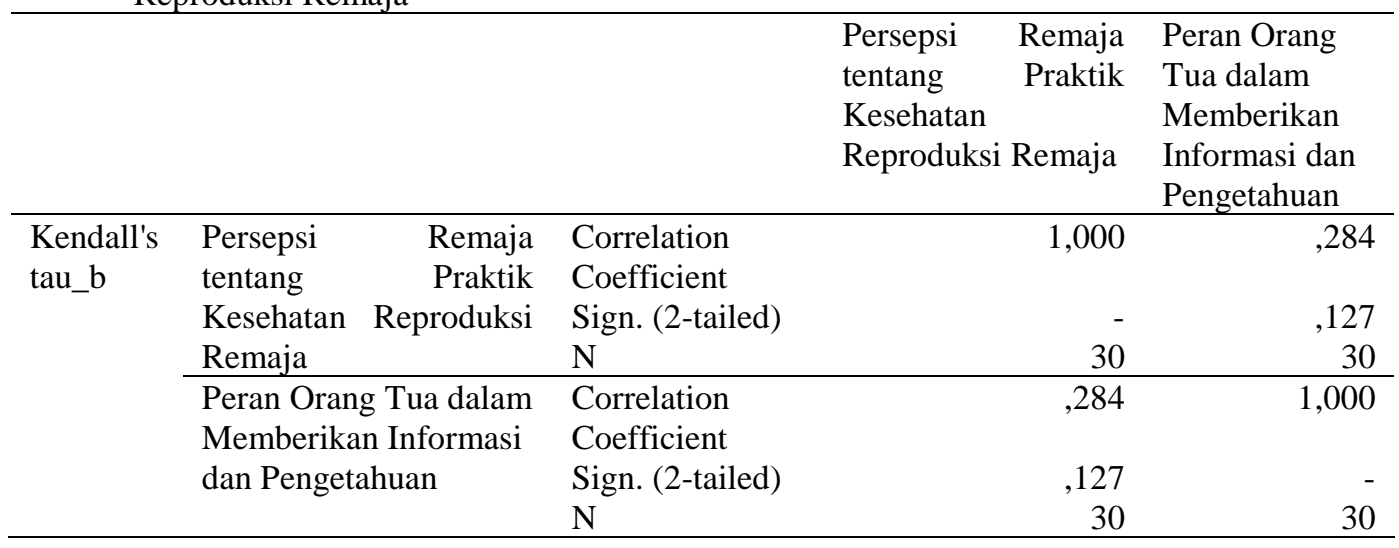

Tabel 6 menunjukkan hasil analisis diperoleh nilai koefisien korelasi sebesar 0,284 dengan nilai signifikansi sebesar 0,127 (> 0,05) menunjukkan bahwa tidak terdapat pengaruh yang signifikan antara peran orang tua dalam memberikan informasi dan pengetahuan tentang kesehatan reproduksi dengan persepsi remaja tentang praktik kesehatan reproduksi remaja.

Tabel 7. Pengaruh Guru yang memberikan Informasi tentang Kesehatan Reproduksi terhadap Persepsi Remaja Tentang Praktek Kesehatan Reproduksi Remaja

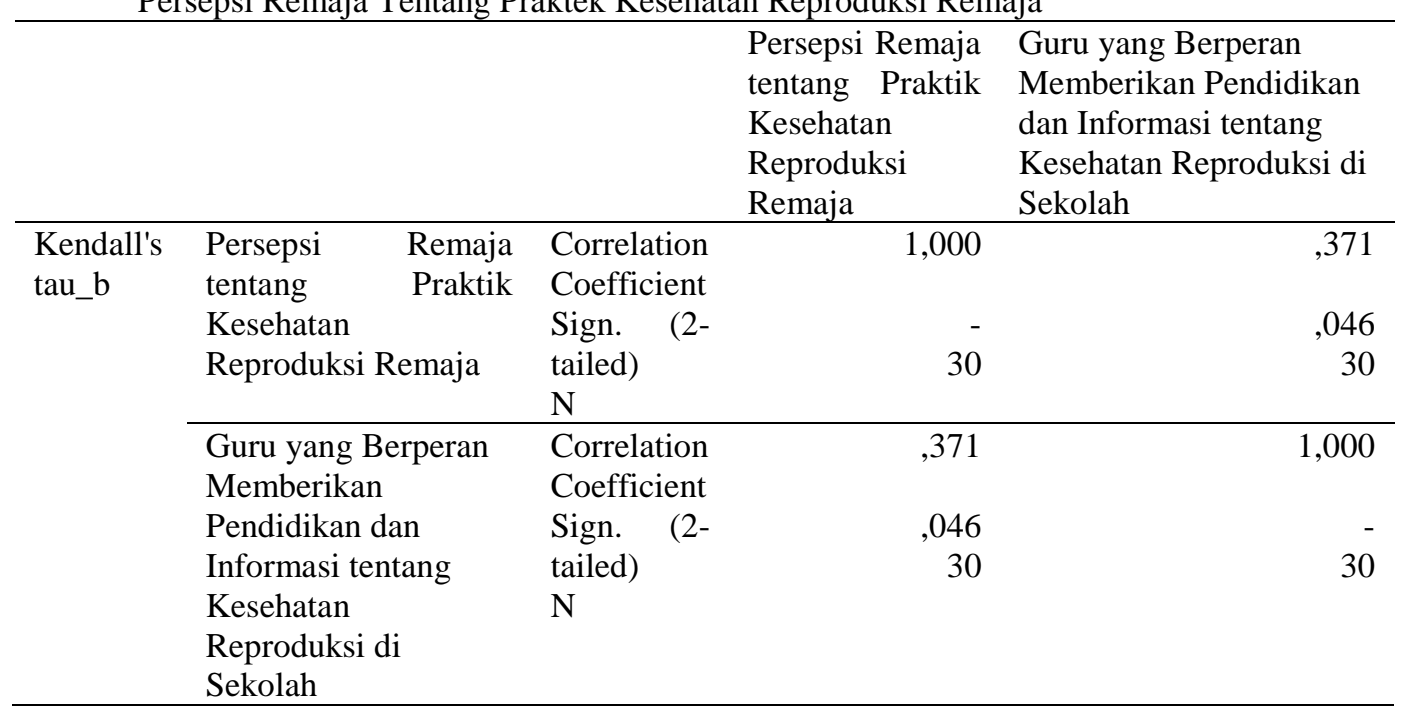


Tabel 7 menunjukkan hasil analisis diperoleh nilai koefisien korelasi sebesar 0,371 dengan nilai signifikansi sebesar 0,046 (< 0,05) menunjukkan bahwa terdapat pengaruh yang signifikan antara peran guru dalam memberikan informasi tentang kesehatan reproduksi dengan persepsi remaja tentang praktik kesehatan reproduksi remaja.

Berdasarkan hasil penelitian dari lima faktor yang dianalisis tentang pengaruhnya terhadap persepsi remaja tentang praktek kesehatan reproduksi remaja menunjukkan bahwa dari kelima faktor tersebut hanya 2 yang memiliki pengaruh yang signifikan terhadap persepsi remaja tentang praktek kesehatan reproduksi remaja yaitu sikap remaja dalam menjaga kesehatan reproduksi dan peran guru dalam memberikan informasi tantang kesehatan reproduksi remaja dengan nilai signifikansi yang sama yaitu 0,046 $(<0,05)$. Adapun hasil analisis faktor peran orang tua dalam memberikan informasi tentang kesehatan reproduksi, tingkat pengetahuan dan frekuensi remaja dalam memperoleh informasi tentang kesehatan reproduksi menunjukkan tidak ada pengaruh.

Hasil penelitian dilakukan ini sejalan dengan penelitian yang telah dilakukan oleh Hikmah (2002) tentang intensitas komunikasi orang tua dan remaja dengan kesenjangan pengetahuan kesehatan reproduksi di SMA Taman Madya Yogyakarta secara kuantitatif dengan pendekatan cross sectional yang menyimpulkan bahwa tidak ada hubungan antara intensitas komunikasi orang tua dan remaja dengan kesenjangan pengetahuan kesehatan reproduksi remaja. Penelitian ini juga sejalan dengan penelitian yang dilakukan oleh Penelitian tentang pengaruh pendidikan kesehatan reproduksi melalui metode pendidikan sebaya terhadap pengetahuan dan sikap remaja dalam pencegahan KTD di SMKN 15 Bandung secara kuantitatif dengan pendekatan eksperimental, yang menyimpulkan bahwa pendidikan kesehatan reproduksi melalui metode pendidikan sebaya berpengaruh pada pengetahuan dan sikap remaja dalam pencegahan KTD, namun ini tidak sejalan dengan penelitian yang dilakukan oleh Setianingsih (2017) yaitu penelitian tentang faktor - faktor yang berhubungan dengan persepsi remaja kelas $\mathrm{x}$ tentang seksual bebas di SMA muhammadiyah bantul Yogyakarta dengan hasil penelitian menunjukkan variabel yang berhubungan dengan persepsi remaja kelas $\mathrm{x}$ tentang seksual bebas yakni variabel akses media informasi dengan $\mathrm{p}$ value $0,02<0,05$.

\section{Kesimpulan}

Tidak terdapat pengaruh tingkat pengetahuan, akses informasi, peran orang tua dalam memberikan informasi tentang kesehatan reproduksi dengan persepsi remaja tentang praktek kesehatan reproduksi remaja.

Terdapat pengaruh pengaruh yang signifikan antara sikap remaja dan peran guru dalam memberikan informasi tentang kesehatan reproduksi dengan persepsi remaja tentang praktek kesehatan reproduksi remaja.

\section{Daftar Pustaka}
[1] BKKBN. Program keluarga berencana nasional. Jakarta: BKKBN. 2001.
[2] BKKBN. Survei demografi dan kesehatan Indonesia 2012: Kesehatan Reproduksi Remaja. Jakarta: BKKBN. 2012 Anak dari Seks Bebas. Jakarta: Grasindo. 2010.
[3] Merry Magdalena. Melindungi
[4] PKBI. Proses Belajar Aktif Kesehatan Reproduksi Remaja. Jakarta: EGC. 2004.
[5] Depkes RI. Pedoman Pelayanan Kesehatan Peduli Remaja di Puskesmas. Direktorat Kesehatan


Keluarga Dirjen Bina Kesehatan Masyarakat. Jakarta: EGC. 2005.

[6] Green, Lawrence W. Health

Promotion Planning : An Educational and Environmental Approach. Second Edition. Mayfield Publishing Company. Mountain View - Toronto London . 2000.

[7] Hikmah. Intensitas Komunikasi Orang Tua dan Remaja dengan Kesenjangan Pengetahuan Kesehatan Reproduksi di SMA Taman Madya Yogyakarta. Tesis. Yogyakarta: UGM. 2002.

[8] Iryanti. Pengaruh Pendidikan Kesehatan Reproduksi Melalui Metode Pendidikan Sebaya Terhadap Pengetahuan dan Sikap Remaja dalam Pencegahan KTD di SMKN 15 Bandung. Tesis. Yogyakarta: UGM. 2003.

[9] Wahyu Ratih Setianingsih. Faktor-faktor yang Berhubungan dengan Persepsi Remaja Kelas X tentang Seksual Bebas di SMA Muhammadiyah Bantul Yogyakarta. Tesis. Yogyakarta: Universitas Aisyiyah. 2017.

[10] Sopiyudin D. Statistik untuk Kedokteran dan Kesehatan. Jakarta: Sagung Seto. 2011. 